\title{
Review Paper: \\ Compression of Antibacterial Effect of Some Herbal Mouthwash Containing \\ Oak Extract: Review Paper
}

Fatemeh Babadi ${ }^{1}$ (D), *Kosar Rezaeifar ${ }^{1}$ (1)

1. Department of Oral and Maxillofacial Medicine, School of Dentistry, Ahvaz Jundishapur University of Medical Sciences, Ahvaz, Iran.

\begin{tabular}{|l|l|}
\hline $\begin{array}{c}\text { Use your device to scan } \\
\text { and read the article online }\end{array}$ & $\begin{array}{l}\text { Citation Babadi F, Rezaeifar K. Compression of Antibacterial Effect of Some Herbal Mouthwash Containing Oak Extract: A Mini Review. } \\
\text { Jundishapur Journal of Medical Sciences. 2021; 20(4):300-311. https://doi.org/10.32598/JSMJ.20.4.2190 }\end{array}$ \\
\hline
\end{tabular}

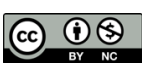

Received: 12 Apr 2021 Accepted: 05 Aug 2021 Available Online: 01 Oct 2021

Keywords:

Oak fruit, Oak tree, Antibacterial, Microorganism, Mouthwash

\begin{abstract}
A B STRACT
Background and Objectives The aim of this present study is to review the effects of antibacterial properties of oak fruit, inner husk of oak fruit, and Jaftex mouthwash.

Subjects and Methods The present study is a narrative literature review conducted using electronic databases such as ISI, PubMed, Scopus, Google Scholar, SID, Magiran, and IranMedex from 1995 to 2019. The keywords that were searched included "Oak fruit", "Oak tree”, "Jaftex mouthwash", "Antibacterial”, "Antimicrobial", and "Microorganism".

Results Review of previous studies showed that oak fruit, Jaft, and Jaftex mouthwash have antimicrobial properties against different microorganisms. Jaftex mouthwash significantly reduced number of microorganisms in mouth, however it had less antimicrobial effect compared to chlorhexidine. Jaftex had a greater inhibitory effect on bacterial growth than Matrica and Persica.

Conclusion Oak fruit and Jaft have antibacterial properties which is related to presence of phenols, tannin, proteins. Various studies confirmed antibacterial property of these types of plants. The antibacterial characteristics of Jaftex mouthwash is mainly related to Jaft extract. Jaftex is recommended as an antibacterial mouthwash.
\end{abstract}

Address: Department of Oral and Maxillofacial Medicine, School of Dentistry, Ahvaz Jundishapur University of Medical Sciences, Ahvaz, Iran Tel: +98 (919) 0791967

E-Mail: kosar.rezaeifar@gmail.com 


\section{مقاله مرورى:}

\section{مقايسه اثر ضدباكتريايى قسمتهاى مختلف تَياه بلوط؛ يك مطالعه مرورى}

فاطمه بابادى' (ن)، "كوثر رضائىفر'

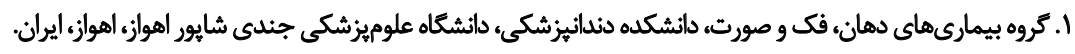

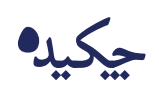

إزمينه و هدف هدف از اين مطالعه بررسى اثرات ضدباكتريايى ميوه بلوط، يوسته داخلى ميوه بلوط و دهائشويه جفتكس است.

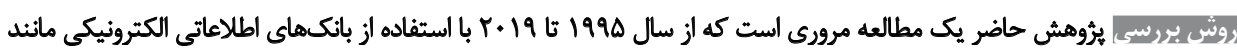

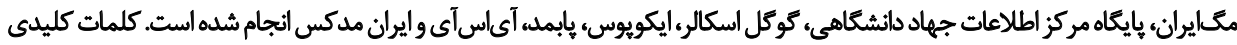

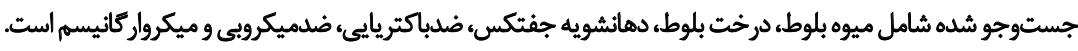

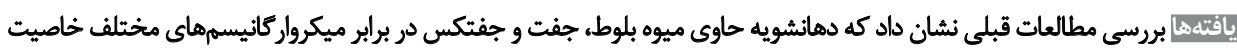

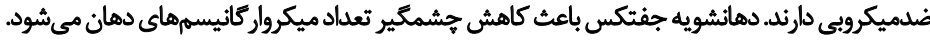

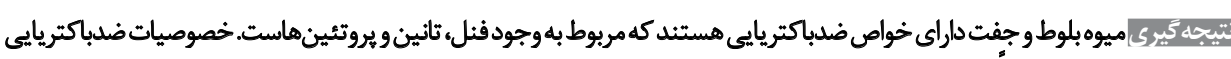

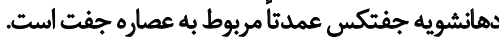

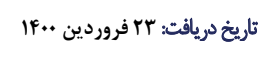

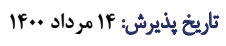

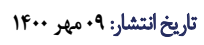

كليدواروها: ميوه بلوط، درخت بلوط، ضدباكتريايي، ميكروار كانيسمه، دهائشئويه

بسيارى از كياهان فعاليت بيولوزيكى خوبى رانشان داده و همين

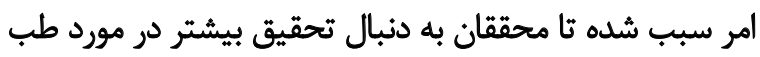

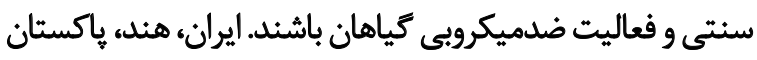

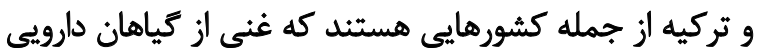

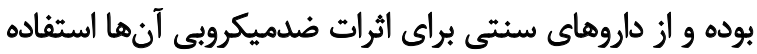

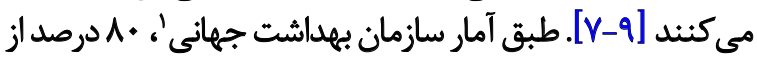

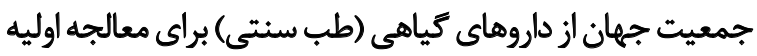

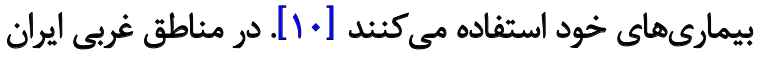

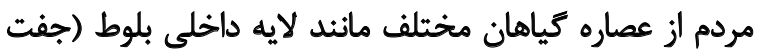

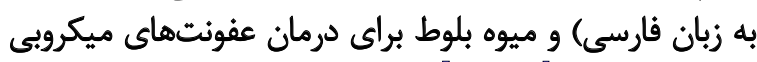

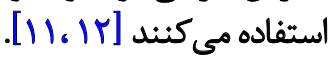

$$
\text { خصوصيات درخت بلوط }
$$

بلوط ايرانى بومى مناطق مركزى، جنوبي و جنوب شرقي رشته

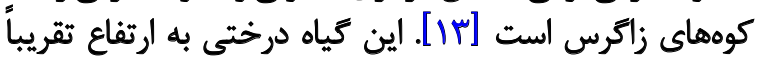

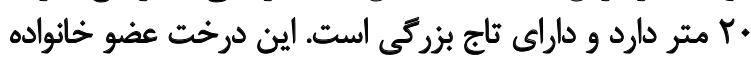

1. World Health Organization

dale

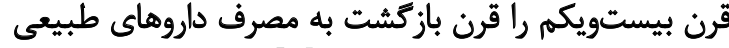

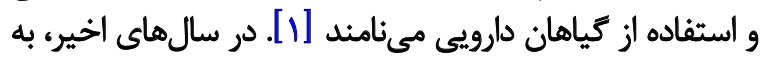

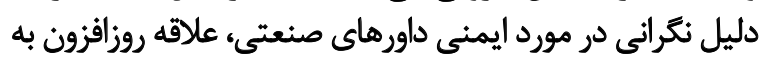

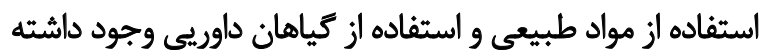

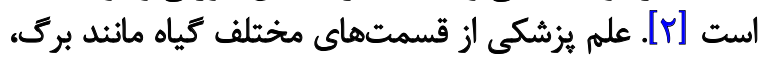

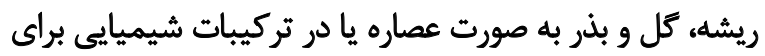

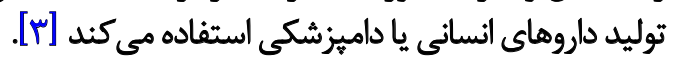
بيمارىهاى عفونى توسط ميكروار كانيسمهاي مختلفى ايجاد

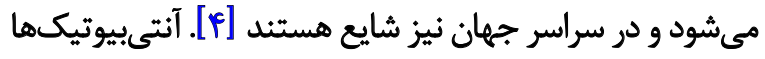

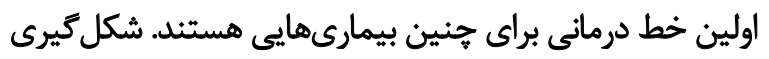

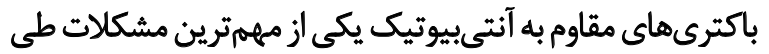

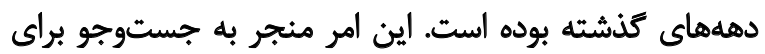

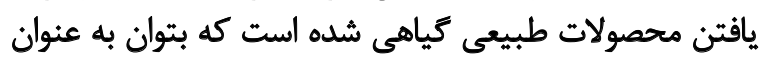
يك عامل آنتى بيوتيكى از آن استفاده كرد [هاهـ]. كياهان دارويى بر اساس فعاليت ضدميكروبى و ميزان اثر آنها

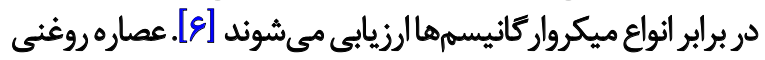




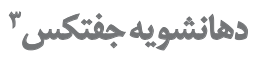

جفتكس دهانشويه كياهي جديدى است كهاز سه جزء إن تشكيل

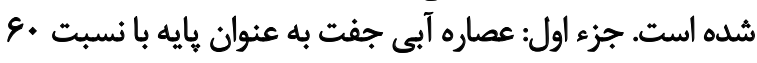

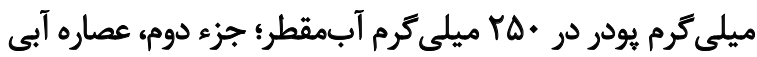

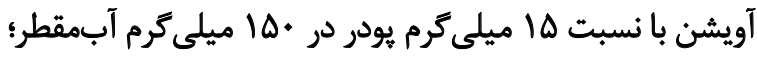

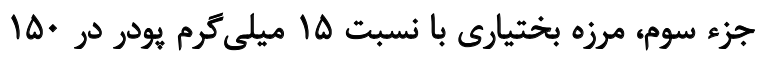
ميلى

اين دهانشويه كياهي در مركز رشد كياهان دارويى دانشكاه

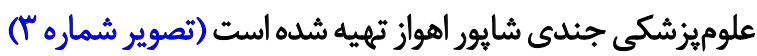

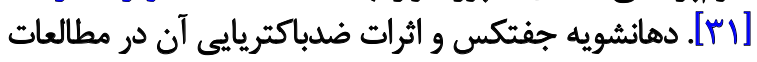

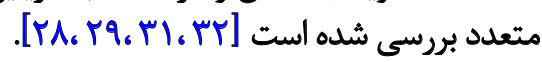

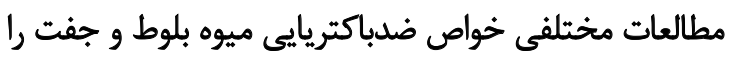

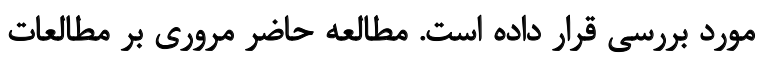

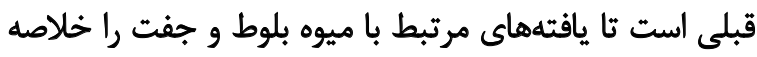

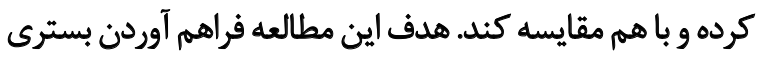

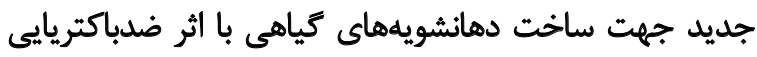

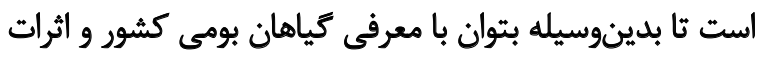

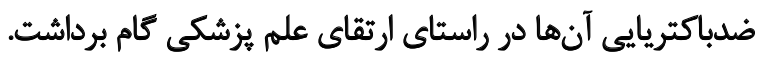

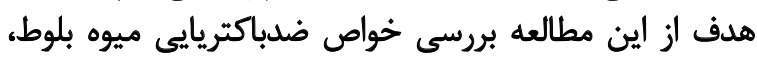
يوست داخلى ميوه بلوط و دهانشويه جفتكس است روش بررسى روش جست بـو مطالعه حاضر يك مطالعه مرورى است. اين مطالعه با استفاده

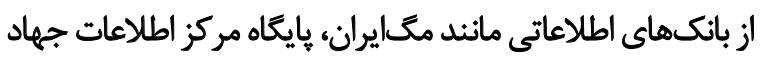

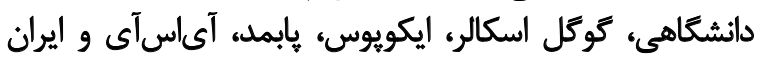

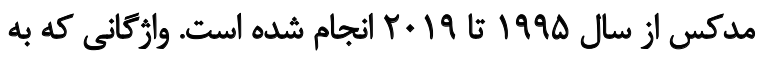

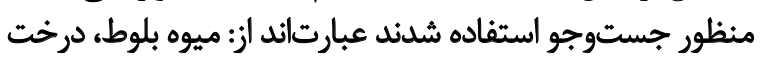

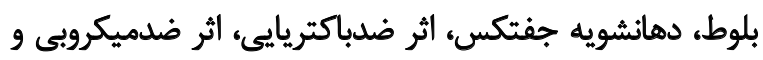

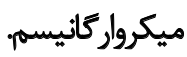

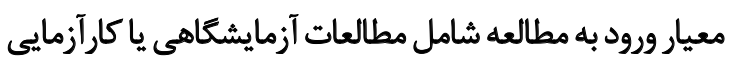

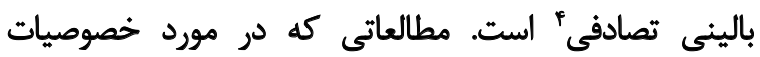

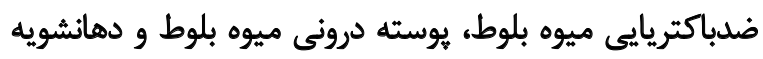

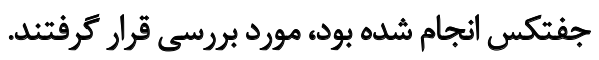

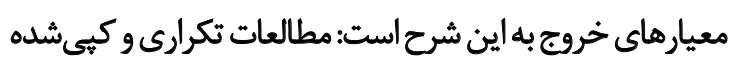
و مقالاتى كه طبقهبيندى نشدهاندا

3. Jaftex

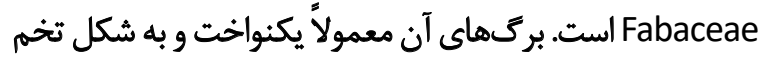

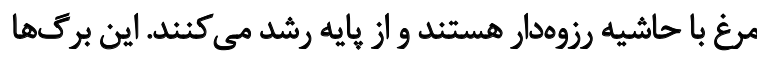

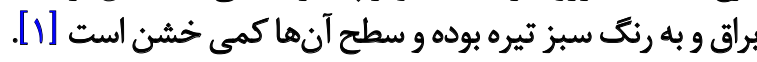
ميوههاى بلوط صاف و بيضى شكل هستئد كه در يك كلاهك

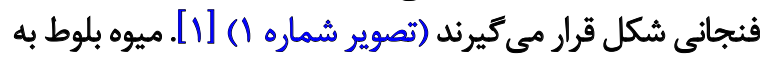

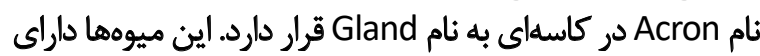

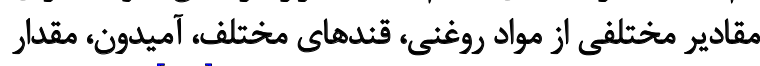

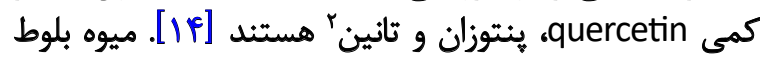

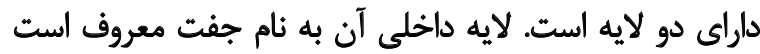

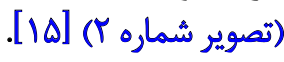

جفت زمانى كه در معرض نور قرار مئيريرد به دليل

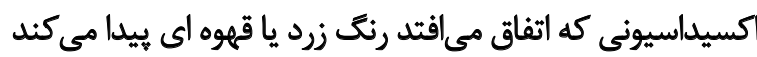

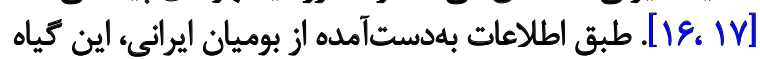

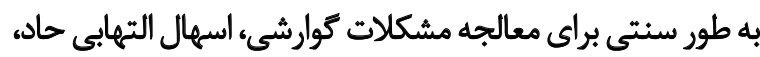

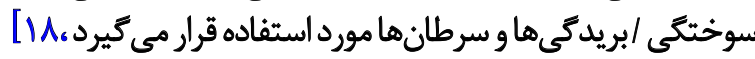

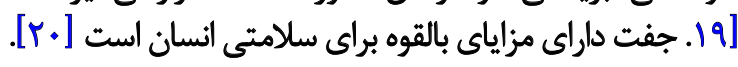

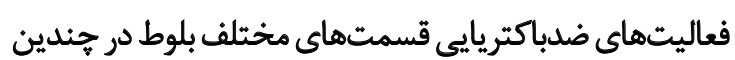

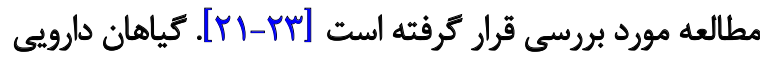

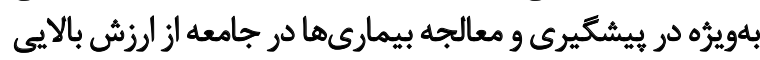

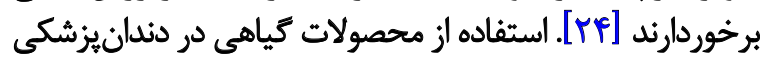

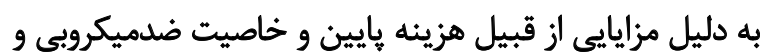

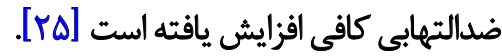

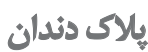

حفره دهان محيط مناسبى براى لانهكزينى و رشد طيف

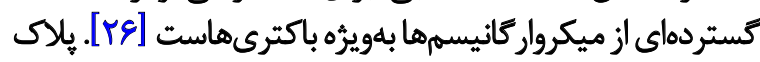

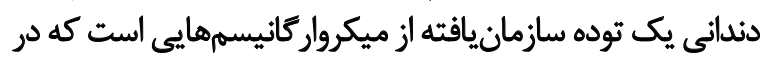

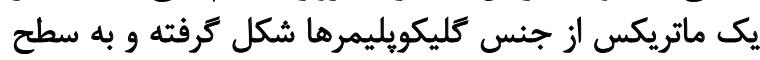

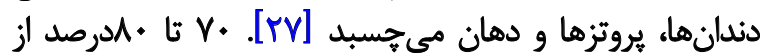

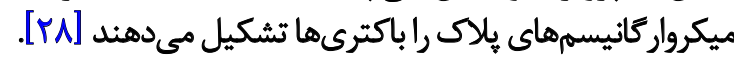
dyguilos

دهانشويه محلول مايعى است كه براى شستوشوى حفره

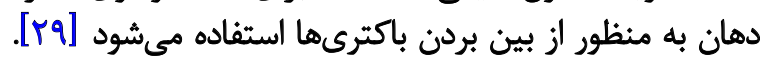

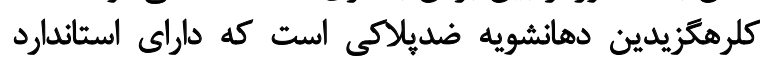

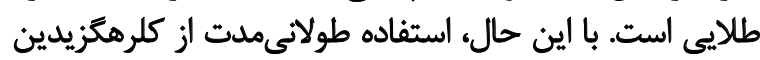

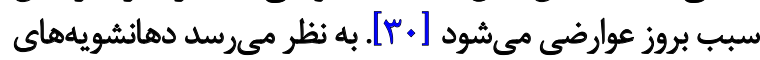

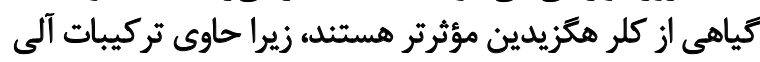

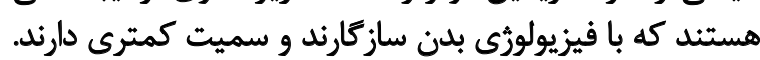

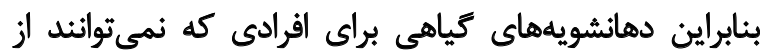

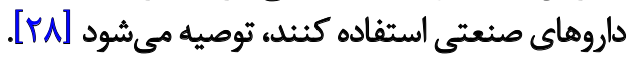


ابراهيمى و همكاران، اثرات ضدباكتريايى و بهبودى زخم توسط

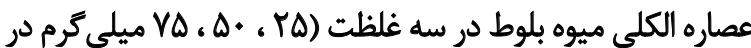

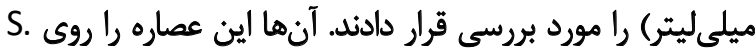

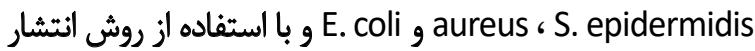

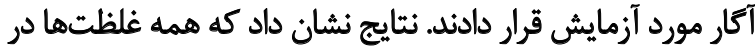

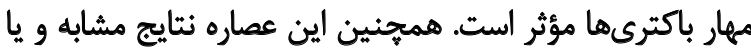

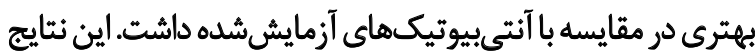

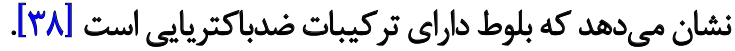

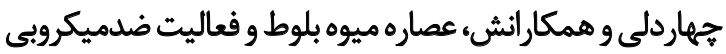

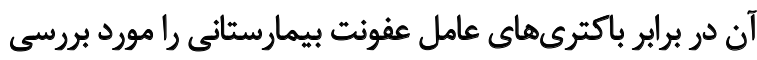

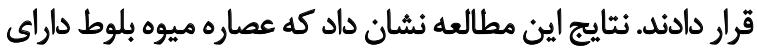

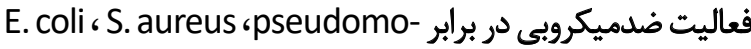
bacillus subtilis gas aeruginosa

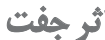

يناهى و همكاران در يك مطالعه آزمايشكاهى، اثر مهارى

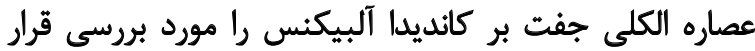

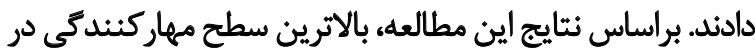

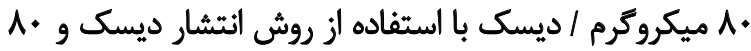

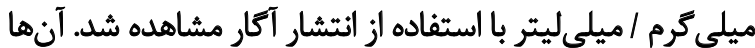

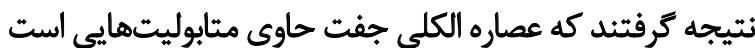

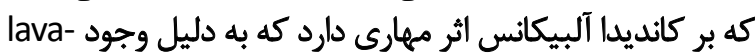
noidas

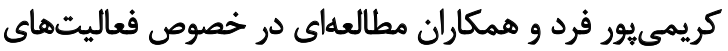

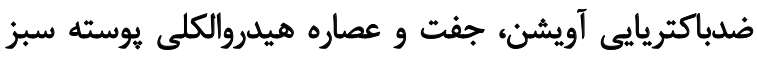

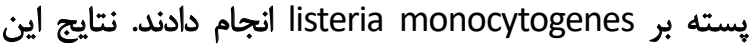

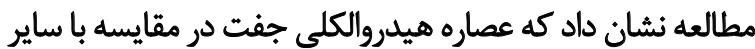

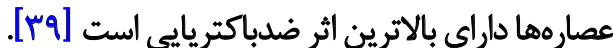
روزكار و همكاران كزارش كردند كه عصاره الكلى جفت اثر

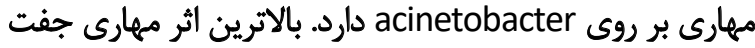

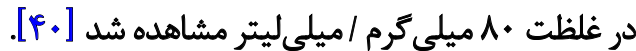
ابراهيمى و همكاران مطالعات بسيارى در مورد خصوصيات

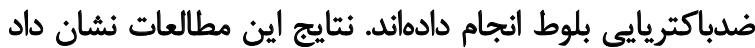

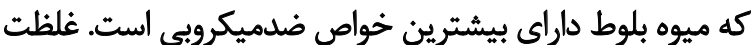

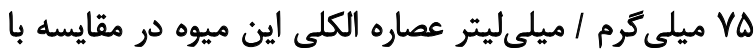

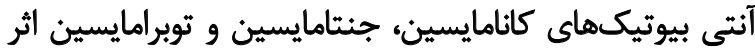

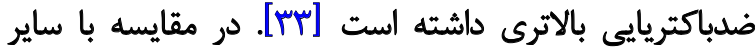

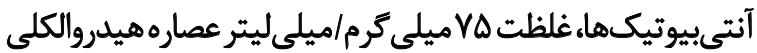

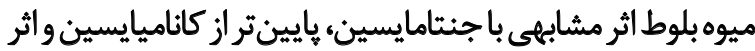

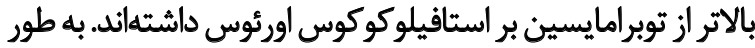

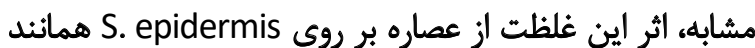

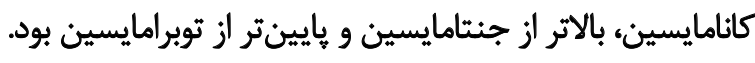

يافتهها

در اين مطالعه 18 مطالعه آزمايشكاهى و دو كارآزمايى بالينى

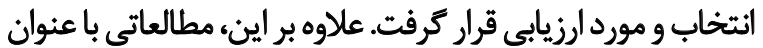

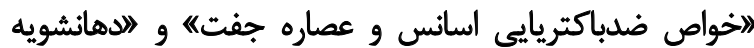
جفتكس" مورد بررسى قرار ترفتند (جدول شماره ().

اثر ميوه بلوط

ابراهيمى و همكاران، در يك مطالعه تجربى به بررسى اثر ائر

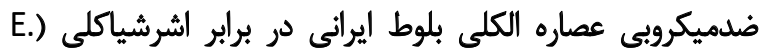

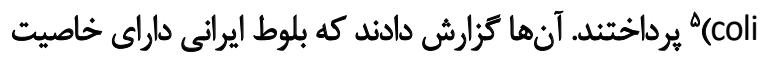

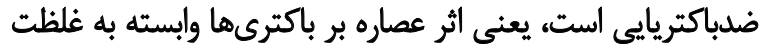

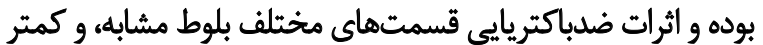

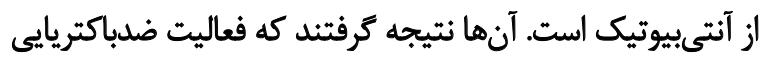

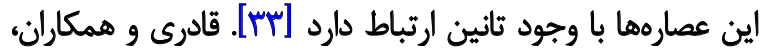

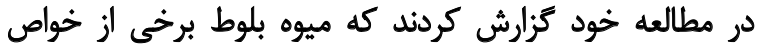

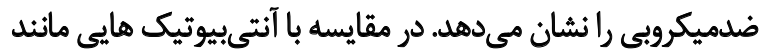

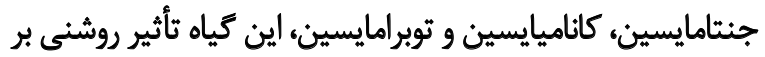

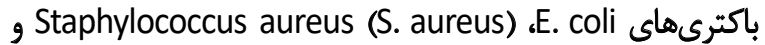
Staphylococcus epidermidis (S. epidermidis) نتيجه كرفتند كه اثر ضدميكروبى ميوه بلوط به دليل وجود تركيبات

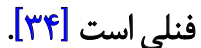

خهاردلى و همكاران، تزارش كردهاند كه عصاره بلوط داراى خاصيت ضدباكتريايي بر - Micro coccus luteus، Yersinia en gterocolitica ،Shigella Dysenteriae ، Salmonella typhi

Citrobacter freundi

ابراهيمى و همكاران اثر ضدباكتريايى عصاره ميوه بلوط بر

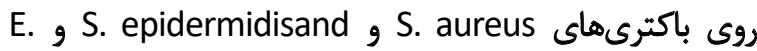
اين إرسى كردند. آنها نتيجه كرفتند كه اثر ضدباكتريايى

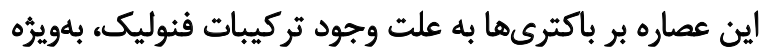

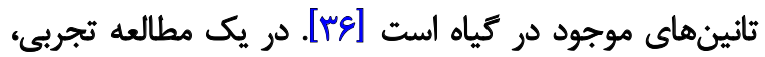

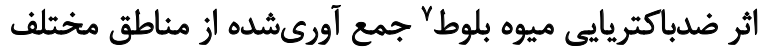

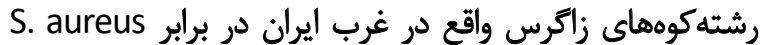
E. coli و Bacillus Sutilis ،Klebsiella Pneumoria انتشار بر ديسك، مورد مطالعه قرار كرفت. بر اساس نتايج اين باين

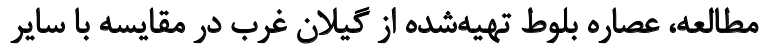

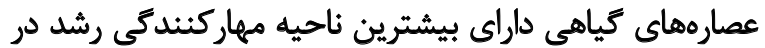

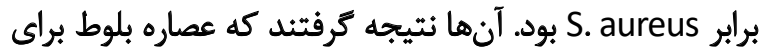

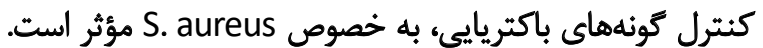

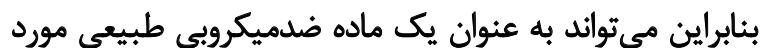

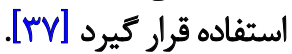

5. Escherichia coli

6. Chahardooli

7. Quercus persica 


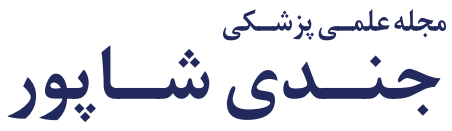

جدول (. ثنايج مطالعات بررسى ششده

\begin{tabular}{|c|c|c|c|c|}
\hline نتايج & ميكروار كانيسم & كياه/ دهاتشويه & سال اتتشار & نويسنده \\
\hline 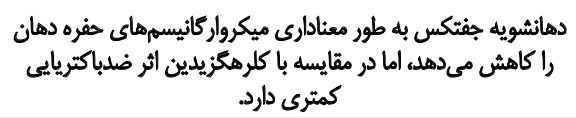 & - & جفتكس & $r+19$ & بابادى و همكاران [آ"] \\
\hline جقتكس در مقايسه با هاتريكا و يرسيكا اثر مهاركندكى رشد بيشتر & $\begin{array}{l}\text { S. mutans, S. sanguinis, } \\
\text { S. salivaris, and Lactoba- } \\
\text { cillus casei }\end{array}$ & دهاتشويلهاى جفتكس، & $r \cdot I R$ & كابادى و همكاران [YA] \\
\hline 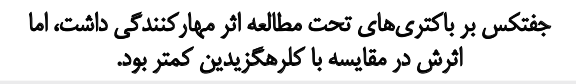 & $\begin{array}{l}\text { S. mutans, S. sanguinis } \\
\text { and S. salivaris }\end{array}$ & جفتكس & $r \cdot M$ & بابادى و همكاران [FV] \\
\hline 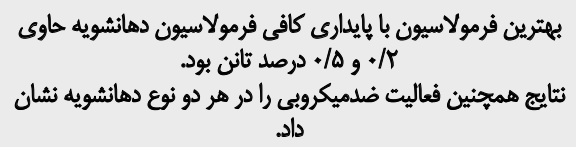 & - & $\begin{array}{l}\text { يوسته بلوط } \\
\text { Quercus brantii } \\
\text { and Zataria }\end{array}$ & $r \cdot u$ & علييور و همكاران [T9] \\
\hline جنتكس شاخص الثهاى و ويلاى را كاهش داد. & - & جفتكس & $r+i r$ & 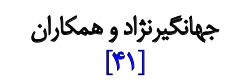 \\
\hline 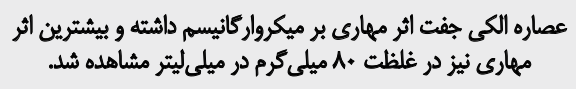 & Acinetobacter & عصاره الكلى جفت & $r+I f$ & روزكار و همكاران [• [\%] \\
\hline عصاره بلوطا |ثر ضدميكروبى مثاسبي بر ميكروار كانيسمها داشت. & $\begin{array}{l}\text { Micrococcusluteus, } \\
\text { Yersinia enterocolitica, } \\
\text { Shigella Dysenteriae, } \\
\text { Salmonella typhi, and } \\
\text { Citrobacterfreundiii }\end{array}$ & عصاره بلوط & $r \cdot I f$ & 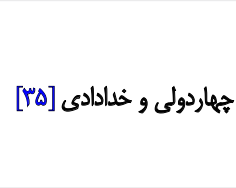 \\
\hline 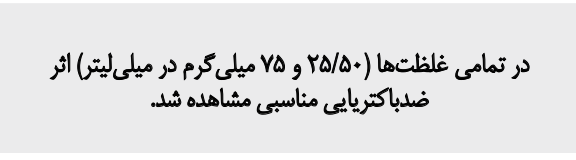 & $\begin{array}{l}\text { E. coli, S. aureus, pseu- } \\
\text { domonas aeruginosa, } \\
\text { and bacillus } \\
\text { subtilis }\end{array}$ & عصاره ميوه بلوط & $r+1 f$ & 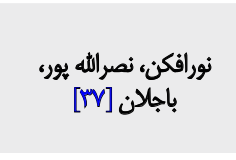 \\
\hline 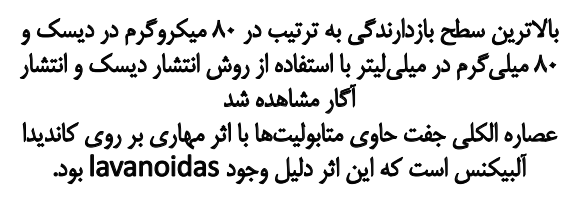 & Candida albicans & عصاره الكلى جفت & rolr & يناهى و همكاران [II] \\
\hline 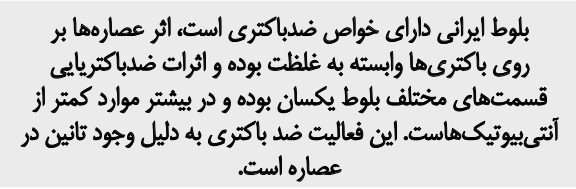 & Escherichia coli & عصاره متانولى بلوطا ايرانى & $r+1 r$ & ابراهيمى و همكاران [Tس] \\
\hline 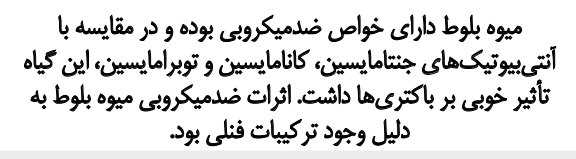 & $\begin{array}{l}\text { Staphylococcus aureus, } \\
\text { E. coli and Staphylococ- } \\
\text { cus epidermidis }\end{array}$ & ميوه بلوط & $r+i r$ & قادرى و همكاران ["in] \\
\hline 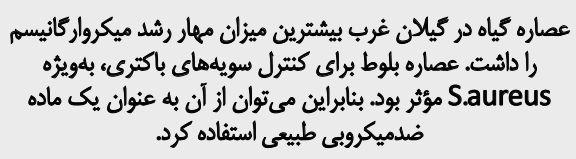 & $\begin{array}{l}\text { S. aureus, S. epidermidis, } \\
\text { E. coli }\end{array}$ & $\begin{array}{l}\text { Quercus persica } \\
\text { fruits }\end{array}$ & $r \cdot I r$ & ابراهيمى و همكاران [TA] \\
\hline
\end{tabular}

عصاره هيدروالكلى جفت در مقايسه با ساير عصارهها اثر ضلميكروبى بيشترى داشت.
Listeria monocytogenes
Hymus denaensis, Jaft, and hydroalcoholic extract of green hull pista-

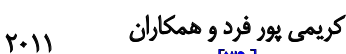
cia atlantica

\begin{tabular}{|c|c|c|c|c|}
\hline اثثرات ضدباكتريايى عصاره به تركيبات فنلى، بهويزه نانين موجود در & $\begin{array}{l}\text { S. aureus, S. epidermidis- } \\
\text { and E. coli }\end{array}$ & عصاره ميوه بلوط & $r+1$. & ابراهيمى و همكاران [عץ] \\
\hline
\end{tabular}




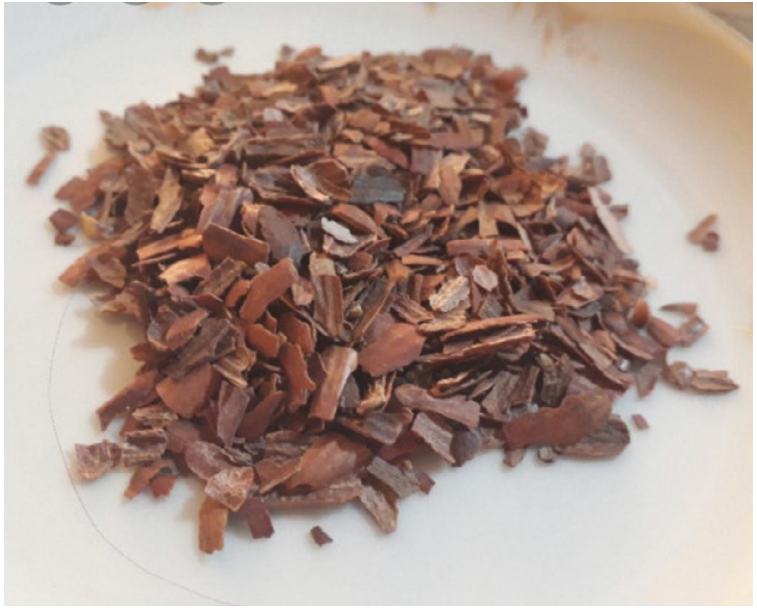

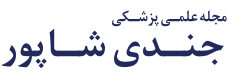

تصوير T. جفت بلوط

با كلرهكَزيدين اثر ضدميكروبى كمترى دارد [إس]]. جهانكيرئراد و

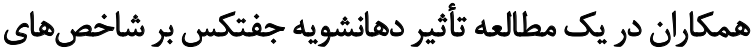

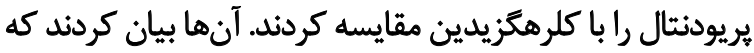

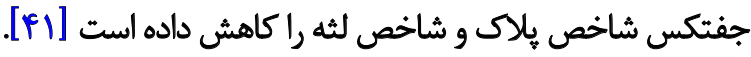

ث

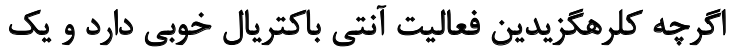

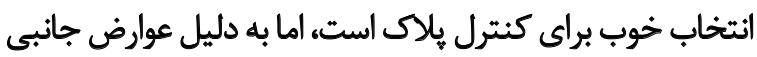

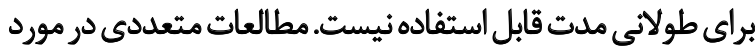

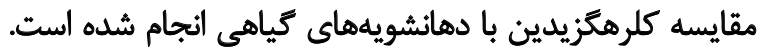

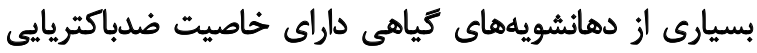

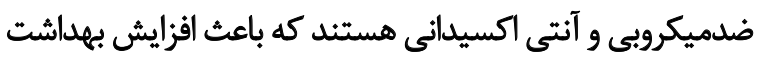

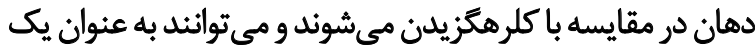

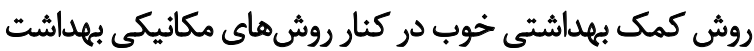

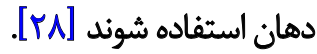

بررسى مطالعات قبلى نشان داده است كه اجزاى مختلف بلوط

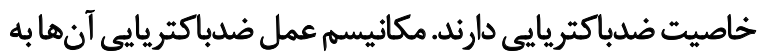

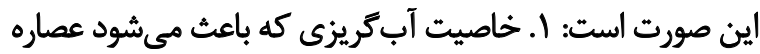

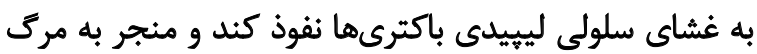

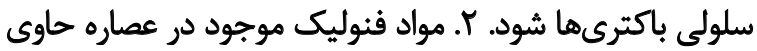
تcarvacrol

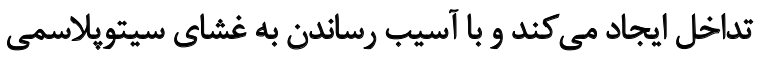

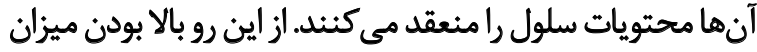

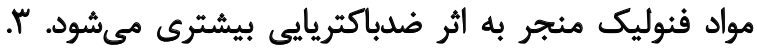

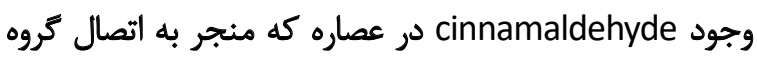

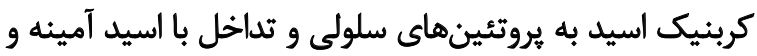

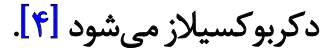

يافتههاى حاصل از تحقيقات يیشين نشان داد با بالا رفتن

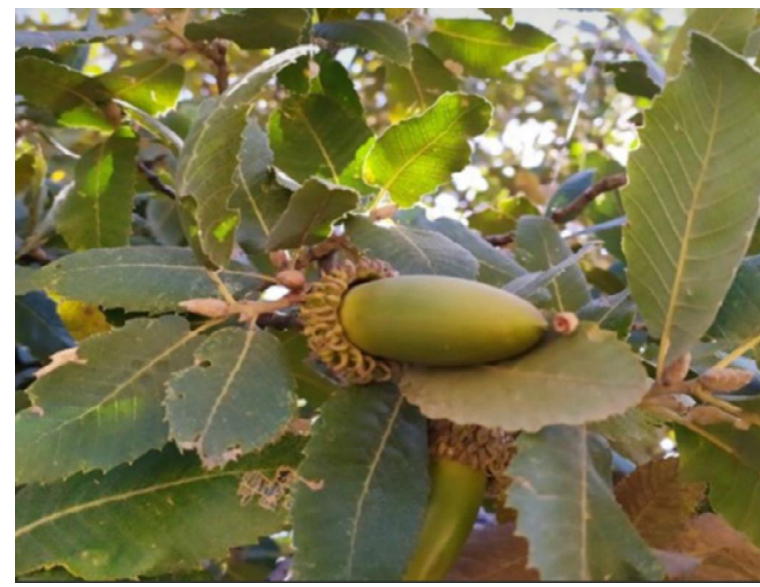

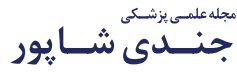

تصوير اـ ميوه درخت بلوط

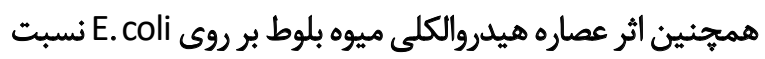

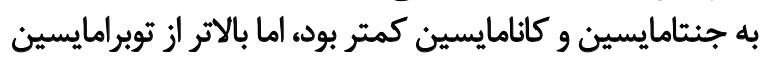

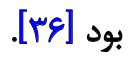
در يك مطالعه توسط علييور و همكاران، فعاليت ضدميكروبى

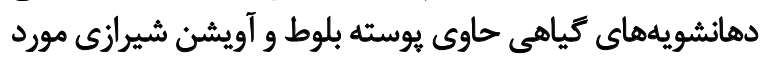

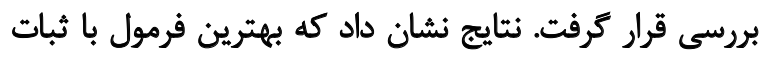

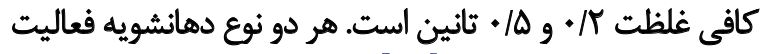

ضدميكروبى رانشان دادند [ra]

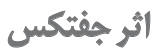

بابادى و همكاران در يك مطالعه اثر ضدباكتريايي دهانشويه

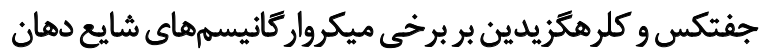

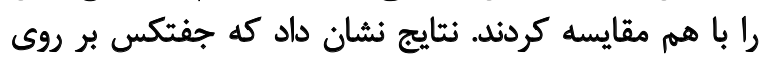

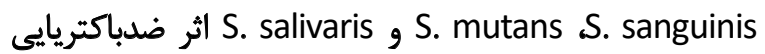

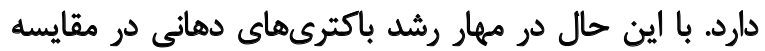

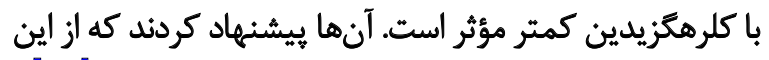

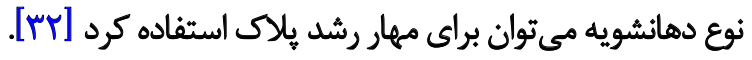
در مطالعهاى كه توسط بابادى و همكاران انجام كرفت اثرات

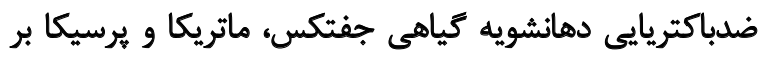

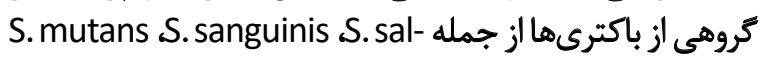

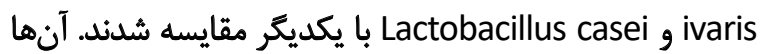

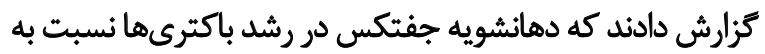

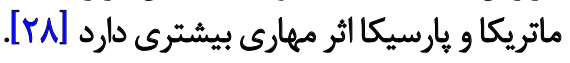
در يك مطالعه بالينى كه توسط بابادى و همكاران انجام

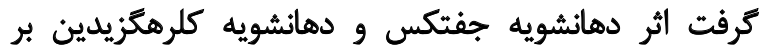

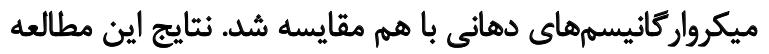

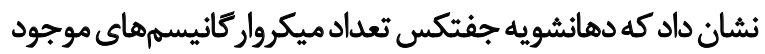

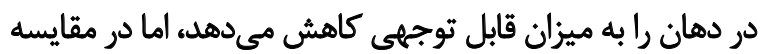




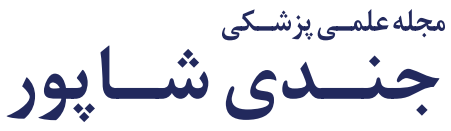

بررسى نتايج مطالعات آزمايشًاهى و بالينى نشان داد كه

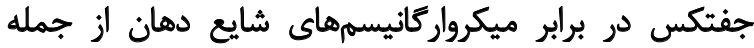

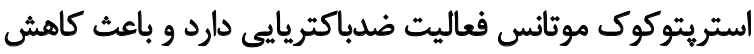

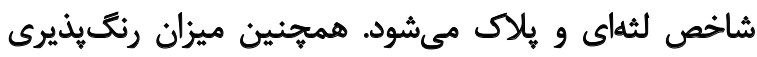

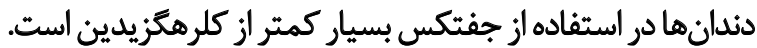

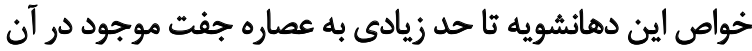

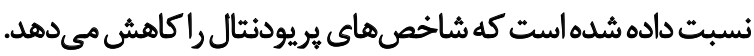

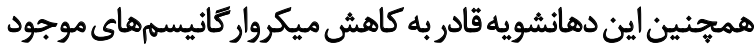

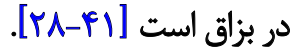

اكرجه اثر ضدباكتريايى اين دهانشويه از كلرهكزيدين كمتر برائر

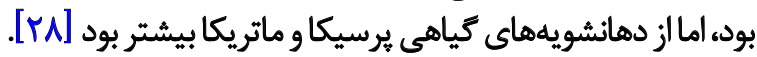
بر اساس نتايج يك مطالعه، آويشن و مرزه بختيارى اثرات

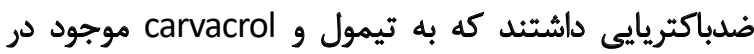

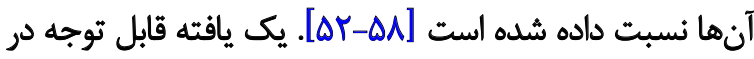

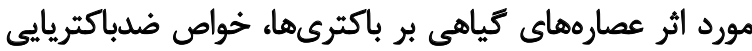

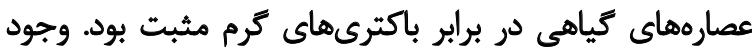

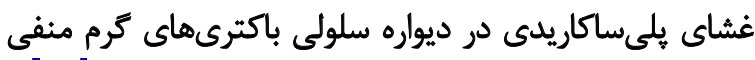

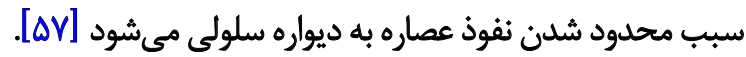

نتايج فوق مىثواند تحولات جديدى در توليدات آيندهنكر

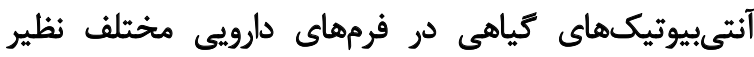

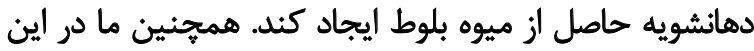

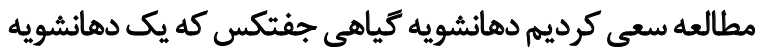

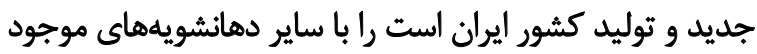

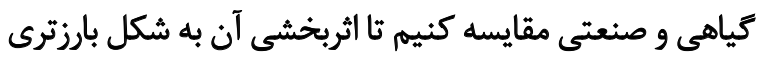

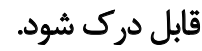

باوجود اين، عدم وجود مطالعات كافى در زمينه كياهان بومى كئ

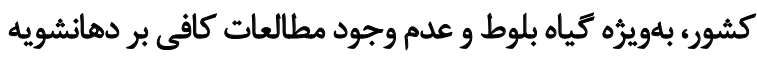

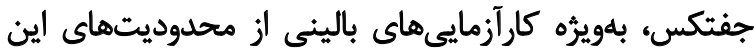

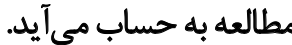

\section{نتيجليَيرى}

كياهان دارويى به واسطه اثرات ضدميكروبىشان نقش حياتى

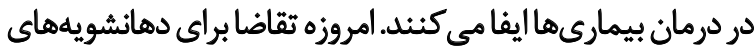

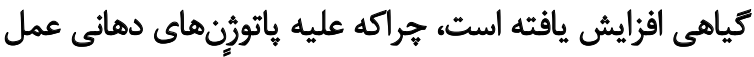

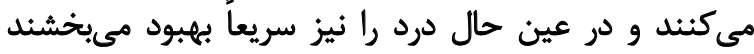

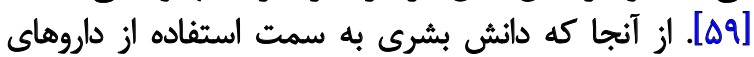

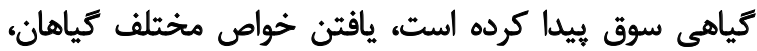

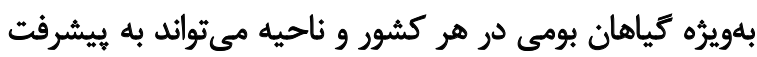

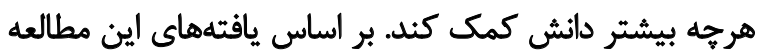

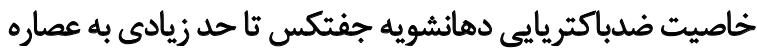

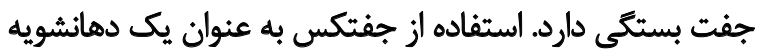

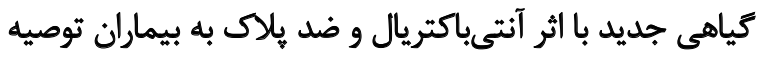

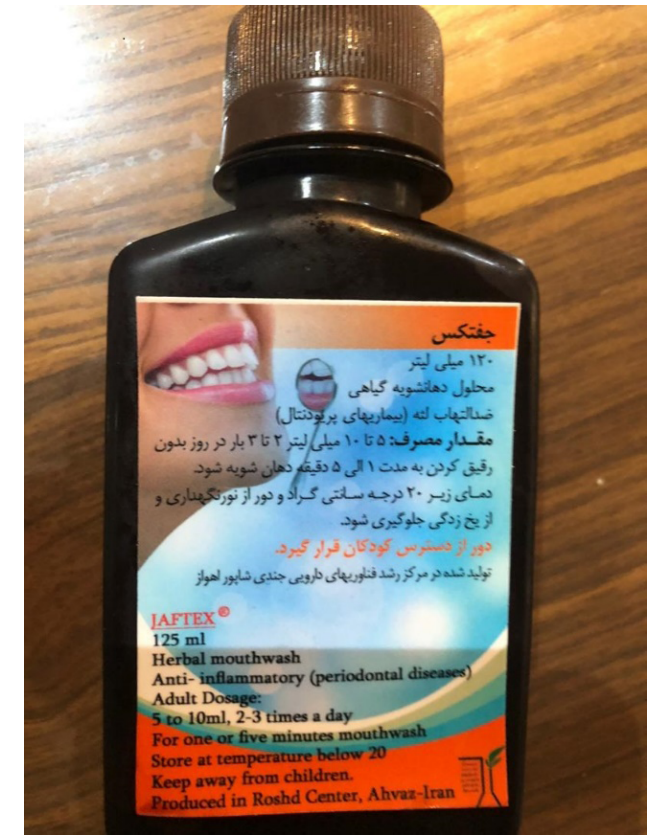

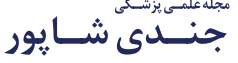

تصوير "ا. دهانشويه جفتكس

غلظت عصاره كياه، اثر ضدباكتريايى آن افزايش مىيابد. اين

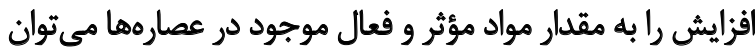

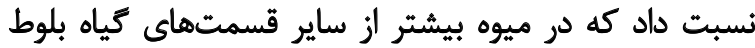

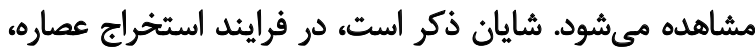

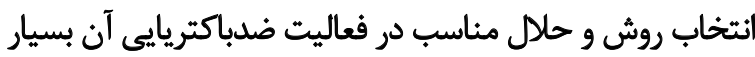

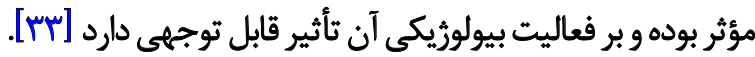

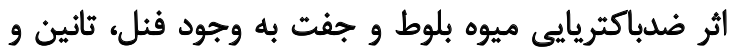

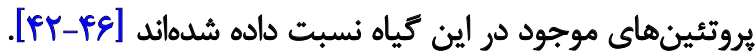

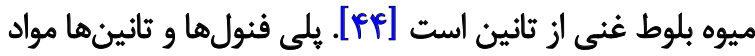

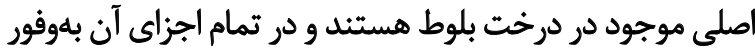

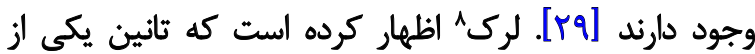

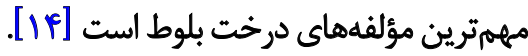

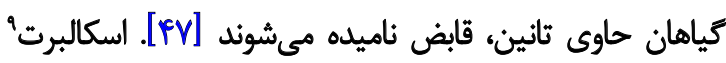

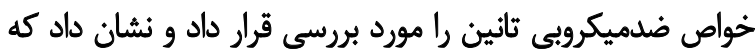

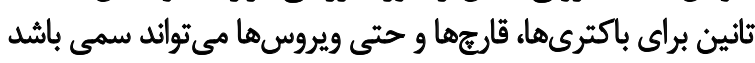

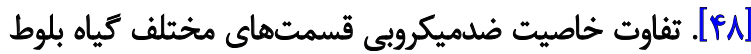

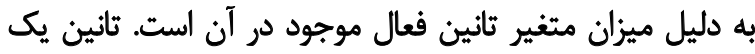

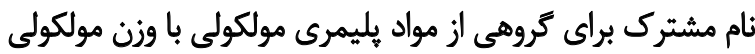

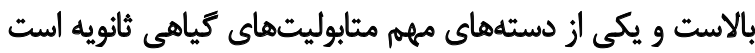

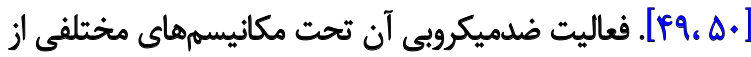

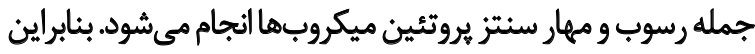

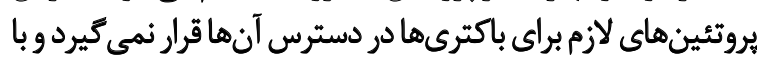

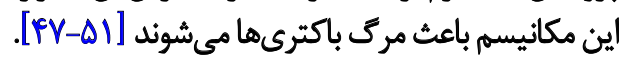

8. Lelerc

9. Scalbert 
مىشود. اجزاى مختلف بلوط داراي خاصيت ضدباكتريايى است و

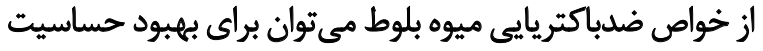

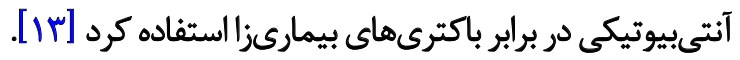

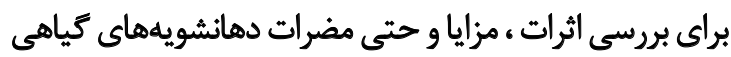

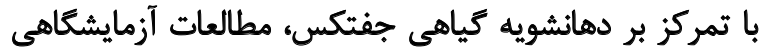
بالينى بيشترى توصيه مى دمانشويه كياهي جفئ.

\section{ماحظات اخلاقى}

يميروى از اصول الخلاق يثوهش

اين مقاله از نوع فراتحليل است و نمونه انسانى و حيوانى نداشته

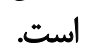

$$
\text { حامي مالى }
$$

اين تحقيق هيج كونه كمك مالى از سازمان هاى تأمين مالى در

بخش هاى عمومى، تجارى يا غير انتفاعى دريافت نكرد.

$$
\text { مشاركت نويسندكان }
$$

هر دو نويسندكان در طراحى، اجرا و نتارش همه بخشهاي ئزوهش حاضر مشاركت داشتهاند.

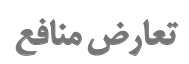

بنابر اظهار نويسندكان اين مقاله تعارض منافع ندارد. 


\section{Refrences}

[1] Sabeti H. [Forests, trees and shrubs of Iran (Persian)]. $3^{\text {rd }}$ ed. Yazd: Yazd University; 2003. http://opac.nlai.ir/opac-prod/bibliographic/660490

[2] Ghasemi Pirbalouti A, Hossayni I, Shirmardi HA. Essential oil variation, antioxidant and antibacterial activity of mountain fennel (Zaravschanica membranacea (Boiss) M. Pimen.). Ind Crops Prod. 2013; 50:443-8. [DOI:10.1016/j.indcrop.2013.07.053]

[3] Nikbakht A, Kafi M. The history of herbal medicine and medicinal plants in Iran. Paper presented at: $8^{\text {th }}$ International PlantPeople Relationship Symposium (IPPS). Jun 2004; Hyogo, Japan. [Link not Found]

[4] Razavi N, Molavi Choobini Z, Salehian Dehkordi M, Saleh Riyahi S, Salehian Dehkordi M, Molavi Choobini S. [Overview of the antibacterial properties of essential oils and extracts of medicinal plants in Iran (Persian)]. J Shahrekord Univ Med Sci. 2016; 17(6):41-52. http://78.39.35.44/article-1-2793-en.html

[5] Okunowo WO, Oyedeji O, Afolabi LO, Matanm E. Essential oil of grape fruit (Citrus paradisi) peels and its antimicrobial activities. Am J Plant Sci. 2013; 4(7B):1-9. [DOI:10.4236/ ajps.2013.47A2001]

[6] Behera S, Khetrapal P, Punia SK, Agrawal D, Khandelwal M, Lohar J. Evaluation of antibacterial activity of three selected fruit juices on clinical endodontic bacterial strains. J Pharm Bioallied Sci. 2017; 9(5):217-21. [DOI:10.4103/jpbs.JPBS_164_17] [PMID] [PMCID]

[7] Ghasemi Pirbalouti A. Medicinal plants used in Chaharmahal and Bakhtyari districts of Iran. Herba Pol. 2009; 55(2):69-77. https://www.researchgate.net/publication/235329717

[8] Mahasneh AM, El-Oqlah AA. Antimicrobial activity of extracts of herbal plants used in the traditional medicine of Jordan. J Ethnopharmacol. 1999; 64(3):271-6. [DOI:10.1016/S03788741(98)00132-9]

[9] Navarro V, Villarreal ML, Rojas G, Lozoya X. Antimicrobial evaluation of some plants used in Mexican traditional medicine for the treatment of infectious disease. J Ethnopharmacol. 1996; 53(3):143-7. [DOI:10.1016/0378-8741(96)01429-8]

[10] Vashist H, Jindal A. Antimicrobial activities of medicinal plants - review. Int J Res Pharm Biomed Sci. 2012; 3(1):222-30. https://www.researchgate.net/file.PostFileLoader.html?id=5706289e615e2705f53cc380\&assetKey= AS:348169167753216@1460021406217

[11] Panahi J, Havasian MR, Pakzad I, Davudian A, Jalilian F, Jalilian A. In vitro inhibitory effect of alcoholic extract of inner stratum of oak fruit (jaft) on Candida albicans. J Pharm Biomed Sci. 2013; 3(1):5-8. https://www.textroad.com/pdf/JPBS/J.\%20 Pharm.\%20Biomed.\%20Sci.,\%203(1)5-8,\%202013.pdf

[12] Moore J, Perkins A. Evaluating antimicrobial efficacy and cost of 3 dressings containing silver versus a novel antimicrobial hydrogel impregnated gauze dressing containing Oakin, an oak extract. Adv Skin Wound Care. 2010; 23(12):544-51. [DOI:10.1097/01.ASW.0000391187.89587.2f] [PMID]
[13] Yarmand MS, Fadavi A, Labbafi Mazrae Shahi M, Sharifi F, Kheiralipour K. Biophysical, biomechanical and bioproximate properties of Iranian oak fruit. J Agric Technol. 2012; 8(4):133542. http://www.ijat-aatsea.com/pdf/v8_n4_12_July/16_ IJAT_2012_8_4_M.S.pdf

[14] Motevaselian M. [Measurement of extractive materials of Quercus infectoria for foodstuff and medicinal value of it (Persian)] [PhD. dissertation]. Tehran: University of Tehran; 1980. https://ganj.irandoc.ac.ir/\#/articles/b27e256dbd5963fff$61478420 \mathrm{bff} 45 \mathrm{ff}$

[15] Babadi F. Effect of Zataria multiflora, satureja, oak fruit husk, and jaftex mouthwash on treatment of recurrent minor oral aphthous stomatitis. Jundishapur J Health Sci. 2020; 12(2):e100883. [DOI:10.5812/jjhs.100883]

[16] Khosravi AD, Behzadi A. Evaluation of the antibacterial activity of the seed hull of Quercus brantii on some gram negative bacteria. Pak J Med Sci. 2006; 22(4):429-32. https://pjms.com. $\mathrm{pk} /$ issues/octdec06/article/article14.html

[17] Mirzaei A, Mirzaei N. Acute and chronic toxicity of Iranian jaft an oak fruit component. Res J Biol Sci. 2012; 7(9):350-4. https:// www.medwelljournals.com/abstract/?doi=rjbsci.2012.350.354

[18] König M, Scholz E, Hartmann R, Lehmann W, Rimpler H. Ellagitannins and complex tannins from Quercus petraea bark. J Nat Prod. 1994; 57(10):1411-5. [DOI:10.1021/np50112a010] [PMID]

[19] Khennouf S, Gharzouli K, Amira S, Gharzouli A. Effects of Quercus ilex $L$. and Punica granatum L. polyphenols against ethanol-induced gastric damage in rats. Pharmazie. 1999; 54(1):756. [PMID]

[20] Jahanshahi GR, Moattar F, Soltani MR. Evaluation of a herbal medicine in the treatment of recurrent aphthous ulcer. J Dent Sch. 2004; 22(1):19-25. https://www.sid.ir/en/journal/ViewPaper.aspx?id $=80523$

[21] Basri DF, Fan SH. The potential of aqueous and acetone extracts of galls of Quercus infectoria as antibacterial agents. Indian J Pharmacol. 2005; 37(1):26-9. [DOI:10.4103/02537613.13851]

[22] Andrenšek S, Simonovska B, Vovk I, Fyhrquist P, Vuorela $\mathrm{H}$, Vuorela P. Antimicrobial and antioxidative enrichment of oak (Quercus robur) bark by rotation planar extraction using ExtraChrom ${ }^{\circledR}$. Int J Food Microbiol. 2004; 92(2):181-7. https://www.sciencedirect.com/science/article/abs/pii/ S0168160503005300

[23] Nourafcan H, Nasrollahpour M, Bajalan I. Antibacterial activity of leaves extract from oak (Quercus persica) against some positive and negative bacteria. Int J Farming Allied Sci. 2013; 2(24):1153-5. http://ijfas.com/wp-content/uploads/2013/12/1153-1155.pdf

[24] Ghassemi F, Momenzade M, Nagafian M, Kargar Jahromi H. [The effect of hydroalcoholic extract of oak fruit husks on liver in rat (wistar) (Persian)]. Pars J Med Sci. 2014; 12(3):1-7. [DOI:10.29252/jmj.12.3.7]

[25] Cavalcanti YW, de Almeida LFD, Costa MMTM, Padilha WWN. Antimicrobial activity and $\mathrm{pH}$ evaluation of calcium hydroxide associated with natural products. Braz Dent Sci. 2010; 13(3/4):49-54. [DOI:10.14295/bds.2010.v13i3/4.686] 
[26] Marcotte H, Lavoie MC. Oral microbial ecology and the role of salivary immunoglobulin A. Microbiol Mol Biol Rev. 1998; 62(1):71-109. [DOI:10.1128/MMBR.62.1.71-109.1998] [PMID] [PMCID]

[27] Babadi F, Amin M, Ahmadi Behbahani F. Evaluation of the antibacterial properties of Lactobacillus acidophilus metabolites against oral plaque streptococci: An in vitro study. J Res Med Dent Sci. 2018; 6(5):198-202. https://www.jrmds.in/articles/ evaluation-of-the-antibacterial-properties-of-lactobacillusacidophilus-metabolites-against-oral-plaque-streptococci-anin-vitro-s.pdf

[28] Babadi F, Amin M, Sharafi N, Saki M. Comparison of the antibacterial effects of jaftex herbal mouthwash with matrica and persica on Streptococcus mutans, Streptococcus sanguinis, Streptococcus salivarius and Lactobacillus casei. J Res Med Dent Sci. 2018; 6(5):349-54. https://www.jrmds.in/articles/ comparison-of-the-antibacterial-effects-of-jaftex-herbalmouthwash-with-matrica-and-persica-on-streptococcus-mutans-streptococcus-.pdf

[29] Alipour Sh, Dehshahri Sh, Afsari A. Preparation and evaluation of a herbal mouthwash containing oak husk of Quercus brantii and Zataria multiflora. Jundishapur J Nat Pharm Prod. 2018; 13(3):e13420. [DOI:10.5812/jjnpp.13420]

[30] Sharma R, Hebbal M, Ankola AV, Murugaboopathy V, Shetty SJ. Effect of two herbal mouthwashes on gingival health of school children. J Tradit Complement Med. 2014; 4(4):272-8. [DOI:10.4103/2225-4110.131373] [PMID] [PMCID]

[31] Babadi F, Akbarnezhad M, Amin M, Saebi Kh. Effect of jaftex and chlorhexidine mouthwashes on oral microorganism: A comparative study. J Res Med Dent Sci. 2019; 7(2):20-4. https://www.jrmds.in/articles/effect-of-jaftex-and-chlorhexidine-mouthwashes-on-oral-microorganism-a-comparativestudy-18209.html

[32] Babadi E, Bamzadeh Z, Babadi F. Comparison of the antibacterial effects of chlorhexidine mouth washes with jaftex mouth wash on some common oral microorganisms (an in vitro study). World Family Med. 2017; 15(9):200-3. [DOI:10.5742/ MEWFM.2017.93125]

[33] 33. Ebrahimi A, Khayami M, Nejati V. [Comparison of antimicrobial effect of different parts of Quercus persica against Escherchia coli 0157:H7 (Persian)]. Q Horiz Med Sci. 2012; 17(4):11-7. http://hms.gmu.ac.ir/article-1-786-en.html

[34] Ghaderi Ghahfarokhi M, Sadeghi Mahoonak A, Alami M, Khomeiri M, Mamashloo S. [Evaluation of antimicrobial activity of the ethanolic extracts from $Q$. branti and Q. castaneifolia fruit against some food-borne pathogens by microdilution method (Persian)]. J Food Technol Nutr. 2012; 9(1):81-94. https://jftn.srbiau.ac.ir/article_1182.html

[35] Chahardoli M, Khodadadi E. [The biosynthesis of silver nanoparticles using oak fruit extract and the investigation of their anti-microbial activities against nosocomial infection agents (Persian)]. J Ilam Univ Med Sci. 2014; 22(4):27-33. http:// sjimu.medilam.ac.ir/article-1-1437-en.html

[36] Ebrahimi A, Khayami M, Nejati V. [Evaluation of the antibacterial activity of Quercus persica jaub \& spach fruit's hidroalcoholic extract in disc diffusion method (Persian)]. J Med Plants. 2010; 9(33):26-34. http://jmp.ir/article-1-308-fa.html
[37] Nourafcan H, Nasrollahpour M, Bajalan I. Antibacterial activity of leaves extract from oak (Quercus persica) against some positive and negative bacteria. IJAAS. 2013; 2(24):1153-5. http://ijfas.com/wp-content/uploads/2013/12/1153-1155.pdf

[38] Ebrahimi A, Khayami M, Nejati V. Evaluation of the antibacterial and wound healing activity of Quercus persica. J Basic Appl Sci. 2012; 8:118-23. https://www.lifescienceglobal.com/ images/Journal_articles/JBASV8N1A19-Ebrahimi.pdf

[39] Karimi Poor Fard M, Mirzaei A, Kargar M, Khosravani SAM, Mohamadi R. [Antibacterial activities of thymus denaensis, jaft and hydro-alcoholic extract of green hull Pistacia atlantica on listeria monocytogenes (Persian)]. Armaghane Danesh. 2012; 17(1):68-77. http://armaghanj.yums.ac.ir/article-1-277-en. $\mathrm{html}$

[40] Roozegar MA, Panahi J, Havasian MR, Pakzad I. Studying the inhibitory effect of alcoholic extract of inner stratum of oak fruit (jaft) and hydro alcoholic extract of summer bulb on acinetobacter in vitro. Int Res J Biol Sci. 2014; 3(6):63-5. http:// www.isca.in/IJBS/Archive/v3/i6/10.ISCA-IRJBS-2014-018.php

[41] Jahanghirnejad M, Babadi F, Safikhani E, Hemmati AA, Amiri $Y$. Comparison of the effects of chlorhexidine mouthwash with jaftex on periodontal index. Jentashapir J Health Res. 2017; 9(1):e11981. https://sites.kowsarpub.com/jjcmb/articles/11981.html

[42] Kaur G, Hamid H, Ali A, Alam MS, Athar M. Antiinflammatory evaluation of alcoholic extract of galls of Quercus infectoria. J Ethnopharmacol. 2004; 90(2-3):285-92. [DOI:10.1016/j. jep.2003.10.009] [PMID]

[43] Sawangjaroen N, SawangjaroenK, Poonpanang P. Effects of Piper longum fruit, Piper sarmentosum root and Quercus infectoria nut gall on caecal amoebiasis in mice. J Ethnopharmacol. 2004; 91(2-3):357-60. [DOI:10.1016/j.jep.2004.01.014] [PMID]

[44] Yousef Elahi M, Rouzbehan Y. Characteriztion of Quercus persica, Quercus infectoria and Quercus libani as ruminant feeds. Anim Feed Sci Technol. 2008; 140(1-2):78-89. [DOI:10.1016/j. anifeedsci.2007.02.009]

[45] Kaur G, Athar M, Alam MS. Quercus infectoria galls possess antioxidant activity and abrogates oxidative stress-induced functional alterations in murine macrophages. Chem Biol Interact. 2008; 171(3):272-82. [DOI:10.1016/j.cbi.2007.10.002] [PMID]

[46] Nabati N, Mojab F, Habibi-Rezaei M, Bagherzadeh K, Amanlou $M$, Yousefi B. Large scale screening of commonly used Iranian traditional medicinal plants against urease activity. Daru J Pharm Sci. 2012; 20:72. [DOI:10.1186/2008-2231-20-72] [PMID] [PMCID]

[47] Motar MLR, Thomas G, Barbosa Fillo JM. Effects of Anacardium occidental stem bark extract on in vivo inflammatory models. J Ethnopharmacol. 1985; 95, 139-42. [DOI:10.1016/j. jep.2004.06.033] [PMID]

[48] Cowan MM. Plant products as antimicrobial agents. Clin Microbial Rev. 1999; 12(4):564-82. [DOI:10.1128/CMR.12.4.564] [PMID] [PMCID] 
[49] Nair R, Kalariya T, Chanada S. Antibacterial activity of some plant extracts used in folk medicine. J Herb Pharmacother. 2007; 7(3-4):191-201. [DOI:10.1080/15228940802152836] [PMID]

[50] Ravanshad S, Basiri E, Mohammadzadeh M. [In vitro evaluation of the antimicrobial effectiveness of Zataria multiflora as an irrigant in infected root canals with Enterococcus faecalis (Persian)]. J Dent. 2009; 10(2):92-8. https://dentjods.sums. ac.ir/article_41332.html

[51] Scalbert A. Antimicrobial properties of tannins. Phytochemistry. 1991; 30(12):3875-83. [DOI:10.1016/00319422(91)83426-L]

[52] Safari R, Adel M, Monji H, Riyahi Cholicheh H, Nematolahi A. [Evaluation of antibacterial effect of some of the endemic herbal essential oils on Streptococcus iniae in invitro (Persian)]. J Aquat Ecol. 2015; 4(4):40-33. http://jae.hormozgan. ac.ir/article-1-166-fa.html

[53] Oke F, Aslim B, Ozturk S, Altundag S. Essential oil composition, antimicrobial and antioxidant activities of Satureja cuneifolia Ten. Food Chem. 2009; 112(4):874-9. [DOI:10.1016/j. foodchem.2008.06.061]

[54] Ghasemi Pirbalouti A, Rahimi E, Moosavi SA. Antimicrobial activity of essential oils of three herbs against Listeria monocytogenes on chicken frankfurters. Acta agric Slov. 2010; 95(3):219-23. [DOI:10.2478/v10014-010-0013-1]

[55] Azaz D, Demirci F, Satil F, Kürkçüoğlu M, Başer KH. Antimicrobial activity of some Satureja essential oils. Z Naturforsch C J Biosci. 2002; 57(9-10):817-21. [DOI:10.1515/znc-2002-91011] [PMID]

[56] Habibian Dehkordi S, Gholipour S, Moshtaghi Broojeni H, Fallah A. [Evaluating antibacterial effects of alcoholic extract of Satureja bactiarica on some foodborne pathogenic bacteria of meat (Persian)]. Vet Res Biol Prod. 2014; 27(3):28-37. [DOI:10.22092/VJ.2014.100967]

[57] Mihajilov-Krstev T, Radnović D, Kitić D. Antimicrobial activity of Satureja L. essential oils against phytopathogenic bacteria Erwinia amylovora. Biol Nyssana. 2010; 1(1-2):95-8. http:// journal.pmf.ni.ac.rs/bionys/index.php/bionys/article/view/63

[58] Burt S. Essential oils: Their antibacterial properties and potential applications in foods - a review. Int J Food Microbiol. 2004; 94(3):223-53. [DOI:10.1016/j.ijfoodmicro.2004.03.022] [PMID]

[59] Nasreen Banu J, Gayathri V. Preparation of antibacterial herbal mouthwash against oral pathogens. Int J Curr Microbiol Appl Sci. 2016; 5(11):205-21. [DOI:10.20546/ijcmas.2016.511.023] 
This Page Intentionally Left Blank 